\title{
Schizophrenia is not disappearing in south-west
}

\section{Scotland}

\author{
J. ALLARDYCE, G. MORRISON, J. VAN OS, J. KELLY, R. M. MURR AY \\ and R. G. MCCREADIE
}

Background Recent work has reported a decline in the incidence of schizophrenia, but it is unclear if these findings reflect a true decrease in its incidence or are an artefact arising from methodological difficulties.

\begin{abstract}
Aims To take account of these methodological difficulties and report service-based incidence rates for schizophrenia in Dumfries and Galloway in south-west Scotland for 1979-98.
\end{abstract}

Method Using both clinical diagnoses and diagnoses generated from the Operational Checklist for Psychotic Disorders (OPCRIT) computer algorithm for ICD-I0 and DSM-IV schizophrenia, we measured change in the incidence rates over time. We used indirect standardisation techniques and Poisson models to measure the rate ratio linear trend.

Results There was a monotonic and statistically significant decline in clinically diagnosed schizophrenia. The summary rate ratio linear trend was 0.77 . However, using OPCRIT-generated ICD-I0 and DSM-IV diagnoses, there was no significant difference over time.

\section{Conclusions OPCRIT-generated}

consistent diagnoses revealed no significant fall in the incidence of schizophrenia. Changes in diagnostic practice have caused the declining rates of clinically diagnosed schizophrenia in Dumfries and Galloway.

Declaration of interest This work was supported by the Stanley Foundation.
Dramatic declines (up to as much as $50 \%$ ) in the first admission rates for schizophrenia have been demonstrated in different countries and continents over the past few decades (Munk-Jørgensen, 1986; Joyce, 1987; Der et al, 1990; Suvisaari et al, 1999). Several of these reports have come from Scotland (Eagles \& Walley, 1985; Geddes et al, 1993). It is still not clear if this replicated finding reflects a true decrease in the incidence of schizophrenia or is simply an artefact (Jablensky, 1997). The uncertainty is due to the considerable methodological difficulties inherent in measuring trends over time in the incidence of schizophrenia. Because it is a rare disorder, its rates are sensitive to distortion by factors such as change in the underlying population structure, change in diagnostic habits, administrative inaccuracies when recording first admission or contact data and change in the organisation and delivery of psychiatric services (Kendell et al, 1993). In this study we set out to take account of these potential confounders and report servicebased incidence rates for schizophrenia in Dumfries and Galloway in south-west Scotland over the 20-year period 1979-1998.

\section{METHOD}

\section{Case identification}

Dumfries and Galloway is a geographically well-defined area in south-west Scotland. It has a stable population of around 147000 , of whom $99.5 \%$ are White. Psychiatric services are provided via one health trust and there is little or no private health care.

We identified all patients in contact with the psychiatric services between the years 1979 and 1998 who were given a clinical diagnosis of one of a broad range of psychotic disorders. During this period two different versions of the International Classification of Diseases (ICD) were used to code cases formally: ICD-9 (World Health Organization, 1978) from 1979 to
March 1996, and ICD-10 (World Health Organization, 1992) thereafter. We reviewed all cases with a diagnosis of schizophrenia (295, F20), schizoaffective disorder (295.6, F25), delusional disorder (297, F22), mania (296.0, 296.2, 296.4, F30, F31.1, F31.2, F31.6), acute, transient or unspecified psychotic disorders (298, F28, F29) or drug-induced disorders (292.1, F12.5, F16.6, F19.5, F12.75, F16.75, F19.75).

This list of possible cases was derived from two sources: data for all in-patients held centrally by the Information and Statistical Division of the Scottish Office (ISD); and locally held registers of outpatients, domiciliary visits and 'out of hours' referrals. Cases were excluded if they had presented with a psychotic episode before 1979 or were not resident in Dumfries and Galloway at the time of their presentation. The case records (including medical, nursing, social work and occupational therapy notes and all correspondence) of the remaining patients with firstepisode psychosis were examined and the Operational Checklist for Psychotic Disorders (OPCRIT) (McGuffin et al, 1991) was completed. The OPCRIT is a symptom checklist containing 90 items, which explores aspects of the mental state examination and the psychiatric history. It has a glossary of clear and explicit descriptions of each constituent item of psychopathology and instructions for coding them. It was designed with case note review in mind. Two of the authors (J.A., G.M.) completed the OPCRIT for the year following the initial presentation. This allowed us to compare each patient using similar information, irrespective of year of presentation. Case notes were examined in random order of date of presentation and raters were blind to the clinically coded diagnosis. There was good interrater reliability for ICD diagnosis of schizophrenia: $\kappa=0.79$ $(P=0.004)$. The OPCRIT checklist was then used to generate ICD-10 and DSM-IV (American Psychiatric Association, 1994) diagnoses via the associated computer algorithm OPCRIT 3.4.

\section{General population data (population at risk)}

The General Register Office of Scotland provided detailed population data for the region. Census data for the years 1971, 1981 and 1991, stratified by age and gender, were provided, and population estimates for the intermediate years were 
interpolated. The under-enumeration in Dumfries and Galloway was estimated at around $1 \%$.

\section{Statistical analyses}

Analyses were carried out in four blocks of 5 years: $1979-83,1984-88,1989-93$ and 1994-98. Incidence rates were calculated, stratified by age and gender, for the years 1979-83. These rates were used as our reference (standard) population rates. Using the indirect standardisation method, we applied this rate to the population structure in the subsequent year blocks. This allowed us to determine the number of expected cases. By dividing the number of cases actually observed by the number of cases expected, we calculated the standardised incidence ratio (SIR). Summary rate ratio linear trend, indicating the summary increase in risk with each consecutive time period, and gender modification effects were calculated using the Poisson Regression Procedure from the STATA program (Stata Corporation,
1999). These analyses were carried out for those patients receiving a clinical diagnosis of schizophrenia: OPCRIT-generated research diagnoses of ICD-10 and DSM-IV schizophrenia, as well as DSM-IV schizophrenia and schizoaffective disorder combined.

\section{RESULTS}

The number of patients with any one of the inclusion diagnoses in contact with the service during the 20-year period was 1460. After excluding cases with a previous psychotic episode prior to 1979 , or whose home address was outside the catchment area, there were 464 cases for which the OPCRIT was completed. There was a monotonic decline (the incidence for each year was less than or equal to the previous one) over the 20-year period in the rates for clinically diagnosed schizophrenia. This was statistically significant. The summary rate ratio trend was 0.77 (95\% confidence

Table I Standardised incidence ratios (SIR)

\begin{tabular}{|c|c|c|c|c|}
\hline Years & No. of observed cases & No. of expected cases & SIR & $95 \% \mathrm{Cl}$ \\
\hline \multicolumn{5}{|c|}{ Using clinical diagnosis of schizophrenia } \\
\hline $1979-83$ & 75 & 75 & 1.00 & $0.79-1.25$ \\
\hline $1984-88$ & 49 & 78.75 & 0.622 & $0.46-0.82$ \\
\hline $1989-93$ & 47 & 81.54 & 0.576 & $0.42-0.77$ \\
\hline $1994-98$ & 32 & 74.65 & 0.429 & $0.29-0.60$ \\
\hline \multicolumn{3}{|c|}{ Summary rate ratio linear trend } & 0.77 & $0.68-0.88$ \\
\hline \multicolumn{5}{|c|}{ OPCRIT-derived ICD-I0 schizophrenia } \\
\hline $1979-83$ & 62 & 62 & 1.000 & $0.77-1.28$ \\
\hline $1984-88$ & 57 & 65.31 & 0.873 & $0.66-1.13$ \\
\hline $1989-93$ & 46 & 67.95 & 0.677 & $0.49-0.90$ \\
\hline $1994-98$ & 62 & 63.40 & 0.978 & $0.75-1.25$ \\
\hline \multicolumn{3}{|c|}{ Summary rate ratio linear trend } & 0.98 & $0.87-1.10$ \\
\hline \multicolumn{5}{|c|}{ OPCRIT-derived DSM-IV schizophrenia } \\
\hline $1979-83$ & 29 & 29 & 1.000 & $0.67-1.44$ \\
\hline $1984-88$ & 24 & 30.58 & 0.785 & $0.50-1.17$ \\
\hline $1989-93$ & 32 & 31.79 & 1.007 & $0.69-1.42$ \\
\hline $1994-98$ & 27 & 29.48 & 0.916 & $0.60-1.33$ \\
\hline \multicolumn{3}{|c|}{ Summary rate ratio linear trend } & 1.01 & $0.85-1.19$ \\
\hline \multicolumn{5}{|c|}{ OPCRIT-derived DSM-IV schizophrenia and schizoaffective disorder } \\
\hline 1979-83 & 52 & 52 & 1.000 & $0.75-1.31$ \\
\hline $1984-88$ & 53 & 54.58 & 0.971 & $0.73-1.27$ \\
\hline $1989-93$ & 45 & 56.51 & 0.796 & $0.58-1.06$ \\
\hline $1994-98$ & 51 & 52.01 & 0.981 & $0.73-1.29$ \\
\hline \multicolumn{3}{|c|}{ Summary rate ratio linear trend } & 0.98 & $0.86-1.11$ \\
\hline
\end{tabular}

interval (CI) 0.68-0.88). However, using OPCRIT-generated diagnoses there was no significant difference in the rates over time, irrespective of the diagnostic system applied. The summary rate ratio linear trend for ICD-10 schizophrenia was 0.98 (95\% CI 0.87-1.10) and for DSM-IV schizophrenia it was 1.10 (95\% CI 0.85-1.19). As previous studies have analysed DSMIV schizophrenia and schizoaffective disorder combined, we did the same; the summary rate ratio trend was $0.89(95 \% \mathrm{CI}$ 0.86-1.11).

As recently published work has shown gender differences in the incidence of schizophrenia (De Alacron et al, 1990; Der et al, 1990), we examined the modification (interaction) effect of gender on the rates over consecutive time periods. There was no significant gender-time interaction in the models. For clinically diagnosed cases, gender-time interaction was 0.89 (CI 0.69-1.16) for OPCRIT ICD-10 schizophrenia it was 0.98 (CI $0.87-1.10$ ) and for OPCRIT DSM-IV schizophrenia it was 0.87 (CI 0.62-1.22).

\section{DISCUSSION}

\section{Methodological issues}

Strength of the study design

(a) This study was carried out in an area with a stable population and no significant ethnic minority groups.

(b) By identifying not only all admissions to in-patient care, but also all day patients, out-patients, domiciliary visits and informal out-of-hours contacts, we avoided possible confounding effects due to the changes in service delivery.

(c) By reviewing all contacts with the service, we identified patients given a diagnosis of a psychotic disorder at first psychiatric presentation and also those psychotic patients who had previous periods of psychiatric care for non-psychotic episodes. This gives the most representative sample of firstever psychosis (Driessen et al, 1998).

(d) Standardised rates were used to ensure that any change in the at-risk population has not led to spurious changes in the incidence rates reported.

(e) Reviewing the case notes of all contacts during the 20 years reduced distortion from inaccurate administrative coding of first contacts.

(f) Finally, any analyses of rates over a long time period will be susceptible to bias 
from gradually changing diagnostic practices, so that by using the OPCRIT checklist and computer algorithm we ensured a consistent diagnostic approach for all patients.

\section{Limitations of the study design}

There are a number of limitations to bear in mind, although we believe they are of minor importance. We report service-based rates for one geographical area. This could introduce bias if the referral patterns of general practitioners changed during the study. However, it is assumed in well-developed services in the UK that nearly all patients with schizophrenia come into contact with services sooner or later (Cooper et al, 1987; Kendell et al, 1993).

Moreover, case note reviews may not be the best way to make a diagnosis. However, OPCRIT has been used successfully in a number of clinical and epidemiological studies (Williams et al, 1996). The two raters in our study were specialist registrars in psychiatry with demonstrated good interrater reliability, and the case notes reviewed were comprehensive. There is, however, a small possibility that the contents of case notes have changed over the study period.

\section{Interpretation of the findings}

We have shown a decline in the first contact rates for clinically diagnosed schizophrenia. This is consistent with previous studies in Scotland (Eagles et al, 1988). There is however no such decline when ICD-10 and DSM-IV diagnostic systems are consistently applied to all cases of psychotic disorders.

The difference between rates for clinically diagnosed schizophrenia and the OPCRIT-generated rates suggests that changes in diagnostic habits have indeed operated to confound the reported rates. The OPCRIT procedure resulted in a number of cases who were clinically diagnosed as suffering from schizophrenia in the early years of the period studied being reallocated to a range of other diagnostic categories, whereas the reverse tended to take place in the later years. This must reflect an increasing hesitancy or caution in making a diagnosis of schizophrenia.

There are at least two possible reasons for this. First, clinicians may now consider reliability of diagnosis important and therefore be using more restrictive operational criteria (Crow, 1990). Second, there may

\section{CLINICAL IMPLICATIONS}

- The incidence of consistently diagnosed schizophrenia has remained constant.

- It is important that early assessment be carried out to ensure that diagnostic hesitancy does not result in delay in starting appropriate management.

- Caution is necessary when using routinely collected data to inform changes in health care provision and service development.

\section{LIMITATIONS}

This is a service-based study.

The data are for one geographical area only.

The study is over a 20 -year period only.

J. ALLARDYCE, MRCPsych, G. MORRISON, MRCPsych, R. G. McCREADIE, FRCPsych, Department of Clinical Research, Crichton Royal Hospital, Dumfries; J. VAN OS, PhD, European School of Neurosciences, Maastricht University, The Netherlands; J. KELLY, MRCP, R. M. MURRAY, FRCPsych, Institute of Psychiatry, London

Correspondence: Dr J. Allardyce, Department of Clinical Research, Crichton Royal Hospital, Dumfries DGI 4TG, Scotland, UK. Tel: +44 1387 244000; Fax: +44 1387 257735;

e-mail: j.allardyce@clinmed.gla.ac.uk

(First received 24 August 1999, final revision 20 December 1999, accepted 21 December 1999)

be an increasing reluctance at the initial presentation to make a diagnosis with such profound prognostic implications without first reviewing all the possible differential diagnoses. That clinicians may now be using narrower criteria for diagnosing schizophrenia has been recognised in several studies (Parker et al, 1985; MunkJørgensen, 1986; Kendell et al, 1993); our findings strongly support this assertion.

The findings of this study are at odds with most of the recently published work investigating trends over time in the incidence of schizophrenia. However, other studies which have closely considered diagnostic difficulties in their methodology have failed to show the magnitude of decline reported in studies depending on routinely collected data (Castle et al, 1991; Brewin et al, 1997). Also, the Scottish ageperiod-cohort study of Takei et al (1996) showed that most of the decline in the incidence of schizophrenia could be accounted for by changes at or near the time of diagnosis rather than by aetiological factors operating early in life.

We conclude that changes in diagnostic practice have resulted in declining rates of clinically diagnosed schizophrenia in the area we have studied. Our results show no sustained fall in the incidence of consistently diagnosed cases of schizophrenia. In southwest Scotland we have found no evidence to support the view that schizophrenia is disappearing.

\section{ACKNOWLEDGEMENTS}

We are grateful to ISD and The General Register Office of Scotland for their help. Our thanks to Mrs M. Muirhead for her administrative assistance and the Stanley Foundation for their financial support.

\section{REFERENCES}

American Psychiatric Association (1994) Diagnostic and Statistical Manual of Mental Disorders (4th edition) (DSM-IV). Washington, DC: APA.

Brewin, J., Cantwell, R., Dalkin, T., et al (1997) Incidence of schizophrenia in Nottingham. A comparison of two cohorts, 1978-80 and 1992-94. British Journal of Psychiatry, I7I, 140-144.

Castle, D., Wessely, S., Der, G., et al (1991) The incidence of operationally defined schizophrenia in Camberwell, 1965-84. British Journal of Psychiatry, I59, 790-794. 
Cooper, J. E., Goodhead, D., Craig, T., et al (1987) The incidence of schizophrenia in Nottingham. British Journal of Psychiatry, I5I, 619-626.

Crow, T. J. (1990) Trends in schizophrenia. Lancet, 335, 851.

De Alacron, J., Seagroatt, V. \& Goldacre, M. (1990) Trends in schizophrenia. Lancet, 335, 513-516.

Der, G., Gupta, S. \& Murray, R. M. (1990) Is schizophrenia disappearing? Lancet, 335, 513-516.

Driessen, G., Gunthner, N., Bak, M., et al (1998)

Characteristics of early- and late-diagnosed schizophrenia: implications for first episode studies. Schizophrenia Research, 33, 27-34.

Eagles, J. M. \& Whalley, L. J. (1995) Decline in the diagnosis of schizophrenia among first admissions to Scottish mental hospitals from 1969-78. British Journal of Psychiatry, 146, I5I-154.

_ , Hunter, D. \& McCance, C. (1988) Decline in the diagnosis of schizophrenia among first contacts with psychiatric services, in north-east Scotland, 1969-1984. British Journal of Psychiatry, 152, 793-798.

Geddes, J. R., Black, R. J., Whalley, L. J., et al (1993)

Persistence of the decline in the diagnosis of schizophrenia among first admissions to Scottish hospitals from 1969 to 1988. British Journal of Psychiatry, 163, 620-626

Jablensky, A. (1997) The 100-year epidemiology of schizophrenia. Schizophrenia Research, 28, III-125.

Joyce, P. R. (1987) Changing trends in first admissions and readmissions for mania and schizophrenia in New Zealand 1974 to 1984. Australian and New Zealand Journal of Psychiatry, 21, 82-86.

Kendell, R. E., Malcolm, D. E. \& Adams, W. (1993) The problem of detecting changes in the incidence of schizophrenia. British journal of Psychiatry, 162, 212-218.

McGuffin, P., Farmer, A., Harvey, l., et al (1991) A polydiagnostic application of operational criteria in studies of psychotic illness. Archives of General Psychiatry, 48, 764-770.

Munk-Jørgensen, P. (1986) Decreasing first-admission rates of schizophrenia among males in Denmark from 1970 to 1984. Changing diagnostic patterns? Acta Psychiatrica Scandinavica, 73, 645-650.

Parker, G., O'Donnell, M. \& Walter, S. (1985)

Changes in the diagnoses of the functional psychoses associated with the introduction of lithium. British Journal of Psychiatry, 146, 377-382.

Stata Corporation (1999) STATA Statistical Software Release 6.0. College Station, Texas: Stata Corp.

Suvisaari, J. M., Haukka, J. K., Tanskanen, A. J., et al (1999) Decline in the incidence of schizophrenia in the Finnish cohorts born from 1954 to 1965. Archives of General Psychiatry, 56, 733-740.

Takei, N., Lewis, G., Sham, P. C., et al (1996) Ageperiod-cohort analysis of the incidence of schizophrenia in Scotland. Psychological Medicine, 26, 963-973.

Williams. J., Farmer, A. E., Archenneil, M., et al (1996) A multi-centre inter-rater reliability study using the OPCRIT computerised diagnostic system.

Psychological Medicine, 26, 775-783.

World Health Organization (1978) The Ninth Revision of the International Classification of Diseases and Related Health Problems (ICD-9). Geneva: WHO.

- (1992) The Tenth Revision of the Internationa Classification of Diseases and Related Health Problems (ICD-10). Geneva: WHO 